Portland State University

PDXScholar

$5-1974$

\title{
Age, Intelligence, and Socioeconomic Status Variance in Preposition Acquisition by Children
}

Georgie Hustead

Portland State University

Follow this and additional works at: https://pdxscholar.library.pdx.edu/open_access_etds

Digitart of the Speech Pathology and Audiology Commons comenens know how access to this document benefits you. Network

Logo

Recommended Citation

Hustead, Georgie, "Age, Intelligence, and Socioeconomic Status Variance in Preposition Acquisition by Children" (1974). Dissertations and Theses. Paper 2175.

https://doi.org/10.15760/etd.2172

This Thesis is brought to you for free and open access. It has been accepted for inclusion in Dissertations and Theses by an authorized administrator of PDXScholar. Please contact us if we can make this document more accessible: pdxscholar@pdx.edu. 
AN ABSRRACT OF IMT THESIS OF Georgio Hastead for the Master of Science in Speech Fathology and hudiulogy presented ray $7,1974$.

Titlo: Age, Intelligence, and Sociöeononic Status Variance in Preposition Acquisition by Children.

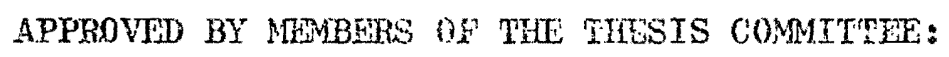

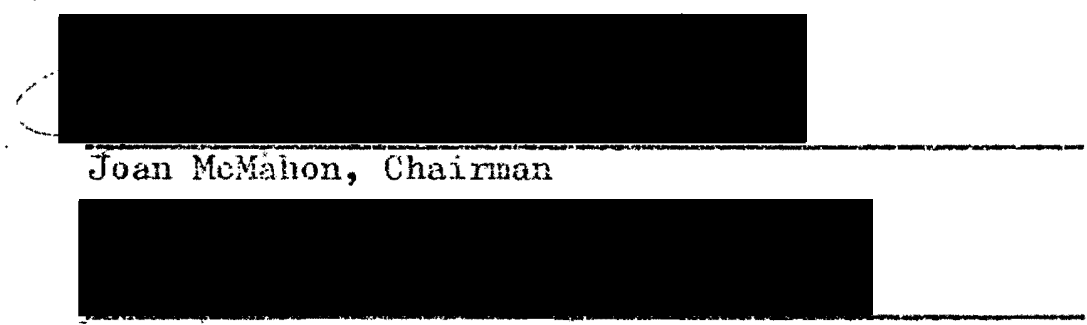

Hobert I. Casteel

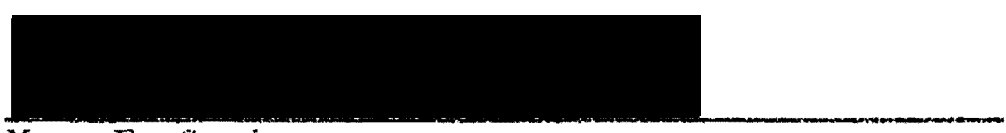

Mary E. Gordon

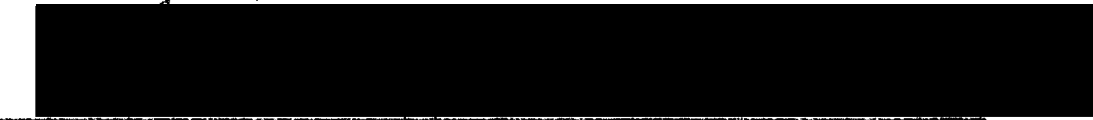

Ronald E. Smith

Numerous linguistic studies have been done to substantiate the importance of prepositions in the English language. However, no romative studies have besn done on the acquisition of expressing prepositions.

The purpose of this investigation was to determine if there were demoustrable trends wich would indicate a need for normative data on the acquisition of trenty-six prepositions tested on the Expressive preposition Test (FPr). The study set cut to detemine at what age levels a giver percentage of the prepositions were expressively acquired 
and if the socioeconomic status (SES) of the child's family would be a detexminer as to the age at which the child would expressively use prepositions. The EPT was administered to a total of thirty-six children between the ages of four and nine years. One-half of the children were from families of low SES and one-half were from families of high SES.

The results show a high correlation between the age of the chil-. dren and their ability to express prepositions. Each age group up through the eight-year-olds expressed a progressively higher percentage of the prepositions. A statement of positive correlation between intelligence-SES and APT-SES was made in that those subjects in the high SES group scored higher on the intelligence quotient and EPT scores. Correlation coefficients indicate a slight coxrelation between the children's intelligence quotient which ranged from 86-115 and their ability to express prepositions. 
AGE, INTELEIGENCE, AND SOCTOECONOMIC STAMUS VARIANCE

IN PREPOSITION ACQUISITION BY CHILIREN

by

GEORGIE HUSTEAD

A thesis submitted in partial fulfillment of the requirements for the degree of

MASTER OF SCIENCE IN SPEECH:

FMPHASIS SPEECH PATHOLOGY AND AUDTOLOGY

Portiand State Iriver:3ity

1974 
TO THE OFFTCE OF GRADUATE STUDIES AND RESEARCH:

The members of the Comittee approve the thesis of Georgie Hustead presented May 7, 1974.

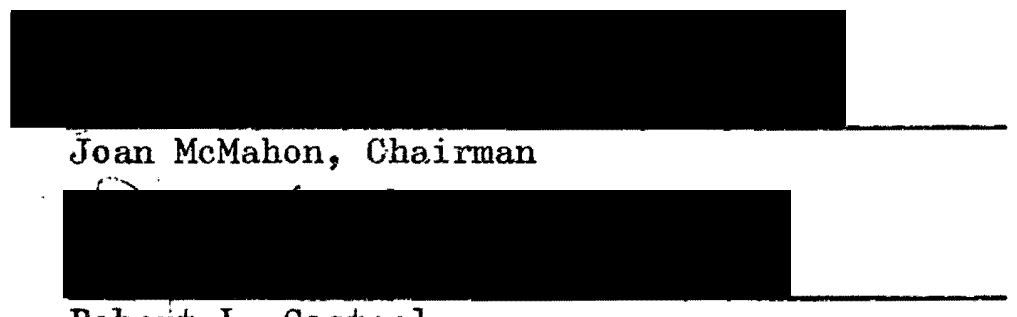

Robert L. Casteel

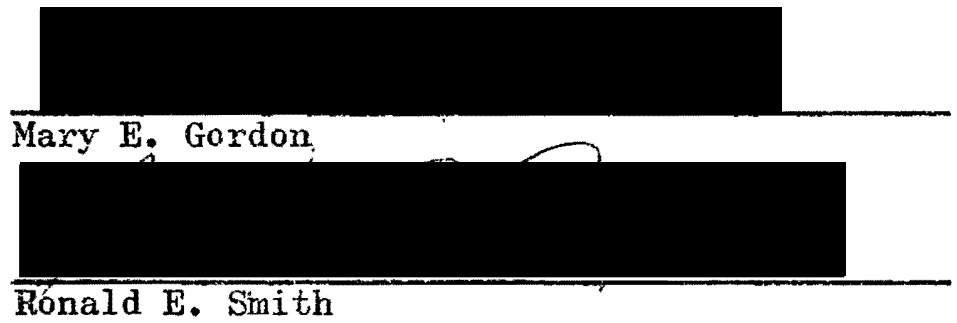

\section{APPROVED:}

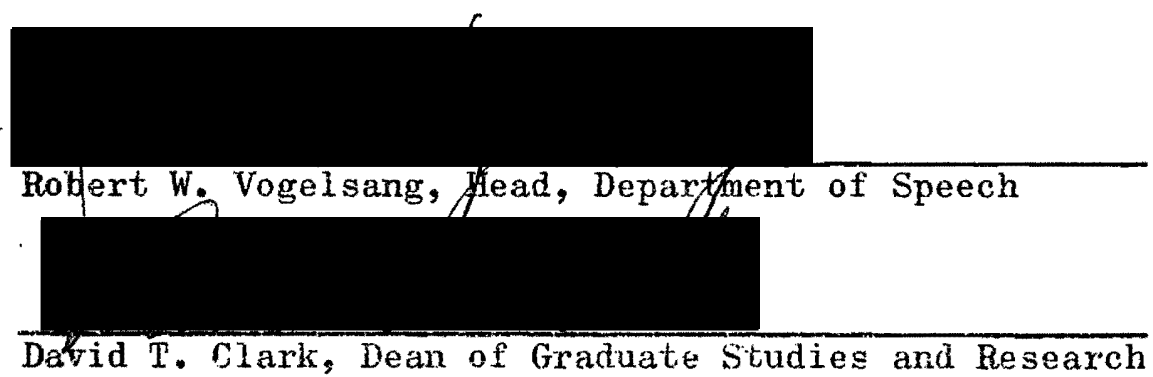

May , 1974. 


\section{ACKNOWLEDGMENTS}

With great pleasure I thank my friend, chairman and graduate advisor, Joan Mckalion, for her time, support, and help so generously given in assistirg to complete this research. I extend my special appreciation to my committee for their belp and support: Dr. Robert L. Casteel (thank you also for your guidance in my personal growth during the last four years), Mary E. Gordon, and Dr. Ronald E. Smith.

I gratefully acknowledge the cooperation very liberally given me by Stanley Girod, principal of Lake Grove School, Joe Favero, speech clinician at Lake Grove School, Sister Francella, principal of Providence Montessori School, and staff members and students at both schools. Without their help this research would not have been possible. I also express with thanks ry appreciation to Dr. Joseph E. Pierce for his continued support and guidance of this study that he helped to create, and to Dr. Quentin Clarkson for his aid and encouragement in completing the research statistics.

To my husband Ron, ny children Ron and Julie, and my in-laws Virginia and Barney Powell, my love and deep appreciation for their support, cooperation, and patience during this time of graduate study. Again, without their enccuragement this regearch would not have been possible. Also, I extend my loving appreciation to my mother, Jane Freedman, for her consistent encouragement. 
TABLE OF CONTENTS

PAGE.

ACKNOWLEDGMENTS . . . . . . . . . . . . . . .

iii

LIST OF TABLES. . . . . . . . . . . . . . .

vi

LIST OF FIGURES . . . • • • • • • • • • • • • •

vi $i$

CHAPritr

I INTRODUCTION. . . . . . . . . . . . . 1

II REVITH OF THE LITERATURE. . . . . . . . . . 4

III METHODS AND PROCEDURES. . . . . . . . . . 19

I METHODS .............. . . . 19

Subjects............. 19

Screening............. 19

II PROCEDURES . . . . . . . . . . . . 20

Evaluation. . . . . . . . . . 20

Scoring . . . . . . . . . . . 21

Data Analysis............ 21

IV WESULIS ALD DISCUSSTON. . . . . . . . . 22

I RESULTS . . . . . . . . . . . . 22

II DISCUSSION . . . . . . . . . . . . . 27 
V SUMMARY AND IMPLICATIONS . . . . . . . . . . . . . .

I SUMMARY. . . . . . . . . . . . . •

II IMPLICATIONS FOR CLINIC AND FUTURE RESEARCH -

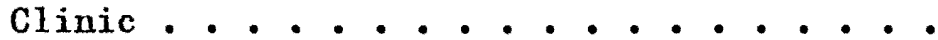

REFERENCES

APPENDIX: SENTENCES USED TO ELICIT THE TWENTY-SIX 
LIST OF TABLES

TABLE

PAGE

I A Psycholinguistic Model of the Production and Comprehension of Utterances ......... 6

II Murch's Perception Model .............. 7

III Comprehension and Expression of Prepositions by Chronological Age .............. 14

IV Comprehension of Prepositions by Chronological Age . . 15

V Percentage of Prepositions Comprehended When Variables of Age and Socioeconomic Status Are Considered . . 16

VI Comprehension and Expression of Prepositions by Chronological Age .............. 17

VII Comprehension and Expression of Prepositions by Chronological Age .............. 18

VII Sumnary of the Statistics for the Expressive Preposition Test Showing the Variables of Age, Intelligence, SES, EPT Score . . . . . . •

IX Analysis of Variance Table for the Expressive Preposition Test . . . . . . . . . . . .

$X$ Matrix of Correlation Coefficients Showing the Variables of Age, Intelligence, SES, EPT Score . .

XI Number of Children at Each Age Level That Correctly Expressed the Individual Prepositions ....... 
vii

\section{LIST OF FIGURES}

FIGURT

PAGE

1 Ranges and means of the EPT scores for the thirty-six children ranging in age from four to nine years . . . . . . . . . . . 


\section{CHAPTER I}

\section{INTRODUCTION}

Numerous linguistic studies have been done with children showing the chronological age development for the phonological, morphological and syntactical development of their language; however, no normative studies have been done on the acquisition of expressing prepositions. Normative data for the acquisition of expressing the various classes of prepositions could be utilized in the clinical setting both to evaluate and implement a program of preposition acquisition for the languagedelayed child.

Linguistic studies have been done to substantiate the importance of prepositions in the English language. Prepositions, often referred to as function words (redefined as minor morphemes by Voegelin, 1957), are used five times as much as major morphemes (labels that categorize the culture) according to Pierce (1963). In counting the major and minor morphemes in any book, the structure of our language is such that there will be approximately the same number used of each category.

Even though the frequency count of major and minor morphemes is approximately the same in a book, a dictionary, whether it be Webster's Third New Intexnational Dictionary (1966) or Webster's Seventh New Collegiate Dictionary (1970), will list several thousand major morphemes and approximately the same 250 minor morphemes (Pierce, 1969). Dewey (1923) performed an analysis on the frequency of 100,000 written 
English words and found the relative frequency of 100 words, all minor morphemes, total 54,303 of the whole 100,000 words.

More specific frequency counts have been done on various parts of grammar, supporting the contention that minor morphemes, including prepositions, are an important part of language acquisition. Zyve (1927) in an extensive study done with third grade children established that nouns (major morphemes) compose 51 per cent of the number of the various words in the children's expressive vocabulary, but the children actually used 15 per cent of the nouns in their running conversations. Zyve indicated that the children comprehended only a small number of prepositions, articles and conjunctions (minor morphemes) but they were used more often in their expressive speech when compared to the total number of words that they understood.

Furthermore, French et al. (1930) substantiated the importance of prepositions, along with other minor morphemes, by monitoring telephone conversations to determine the relative frequency of spoken words. They found that prepositions, auxiliary verbs, pronouns, conjunctions, and articles formed only 5 per cent of the different words, but made up 57 per cent of all spoken words.

They concluded that:

- . conversation is based on a framework built up of a relatively small number of different words, arranged in many patterns, which supports the more variegated words which convey most of the meaning.

Templin (1957) observed that the relative frequency of spoken words is already established by the time a child is three years old. Fries (1940) found that only nine prepositiors accounted for over 90 per cent 
of the prepositions used when a substantial sample of written material was examined. These prepositions, in frequency order, are as follows: "of," "in," "to," "for," "at," "on," "from," "with," and "by."

Since there are at least twenty-six different prepositions in the English grammar, not merely nine, and because prepositions and other minor morphemes are used more frequently in a child's expressive language, it would appear to be of importance to the speech clinician to know in what order the various prepositions are acquired by children, so that a program of preposition acquisition can be implemented for the language-delayed child.

Accordingly, the present study was to determine if there were demonstrable trends which would indicate a need for normative data on the acquisition of the twenty-six different prepositions tested. Answers to two questions were sought:

1. At what age levels is a given percentage of the prepositions expressively acquired?

2. Will the socioeconomic status of the child's family be a determiner as to the age at which the child will expressively use prepositions? 


\section{CHAPTER II}

\section{REVIEW OF THE LITERATURE}

In order to understand how prepositions are acquired, one needs to know how language in general is acquired. Historically, there have

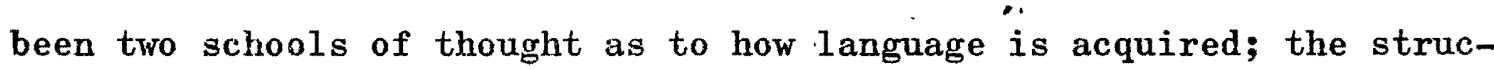
tural linguistic and psycholinguistic research reflect these two different ways of looking at language acquisition.

The structuralist describes the acquisition of language by collecting volumes of empirical data on phonemes, morphemes and the syntactical structure of sentences produced by children at various ages. Smith (1926) and Van Alstyne (1929) did scientific studies on the morphological units of the English language, describing how vocabulary is acquired by children. The various studies referred to in the "Introduction" of this paper are an example of the descriptive studies done on morphological units. Smith (1926), McCarthy (1930), Day (1932), Davis (1937), and Fisher (1934) analyzed the syntactical structure of children's language.

Longitudinal studies on linguistic development have been done by structuralists such as: Gesell (1925, 1928), Buhler (1930), Shirley (1933), Bayley (1933), Gesel1, Thompson and Amatruda (1934, 1938), Buhlex and Hetzer (1935), Gesell, Halverson, Thompson, et al. (1940), and Cattrell (1940). McCarthy (1954) claims that the above studies yielded vainable information oecause they were done with large numbers 
of children and under standardized observational conditions.

The psycholinguist describes the child's linguistic competence or knowledge of his language in temns of understanding the rule that relates sound and meaning in a specific way. Linguistic competence reflects the child's lnowledge of the deep structure of his language. Menyuk (1971) claimed that a child does not acquire his native language from acoustic stimuli alone. Rather, humans have the capacity to search for and accumulate abstractions of their language. Table $I$ shows how some psycholinguists (Menyuk, 1971; Wales and Marshall, 1968) view the organization of linguistic competence. In the table the diagram arrows move both up and down. Thus, it shows that a person can analyze his utterance deductively, (from the general to the specific) top to bottom, or inductively, (from the specific to the general) bottom to top. Menyuk (1971) explains that:

It should be noted that there are also arrows indicating cross references between semantic rules and syntactic rules, between semantic rules and phonological rules, and between syntactic rules and phonological rules, indicating that perhaps tentative bypotheses are reached which are then checked by reference to parts of the system before the final stage of comprehension or production is reached.

Lee (1959) further explained:

The acquisition of language requires much more than memorizing a vocabulary or learning the rules of gramar and syntax. We are dealing with the phenomenon of perception, which, as Bussell Meyers (19it9) has so clearly pointed out, bears a striking resemblance to what the general semanticist calls "abstraction."

Prepositions, like all morphological units of language, are acquired through the process of perception, which occurs when one categrrizes the stimuli that are taken in, identified, sorted and given a 
TABLE I

A PSYCHOLINGUISTIC MODEL OF THE PRODUCTION

AND COMPREHENSION OF UTTERANCES

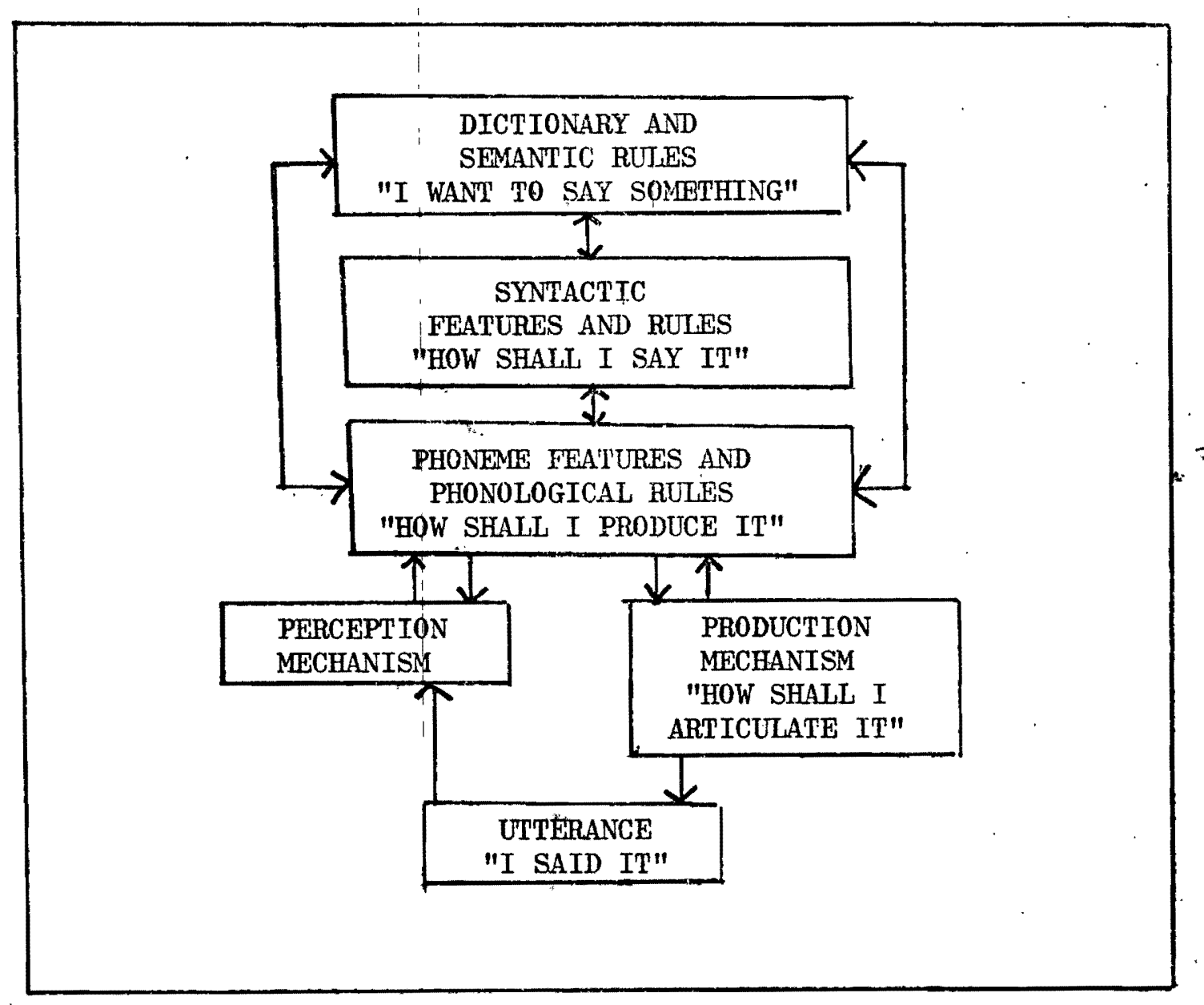

particular meaning. Dr. Gerald Murch (1973), Associate Professor of Psychology, Portland State University, has developed a perceptual process model in which the boxes represent a function. As shown in Table II, the model answers the question of what is happening, but not how the perceptual mechanism works.

Sensory Register: The analysis of physical characteristics takes place here, based on long-term memory. The first point at which 
TABLE II

MURCH'S PERCEPTION . MODEL

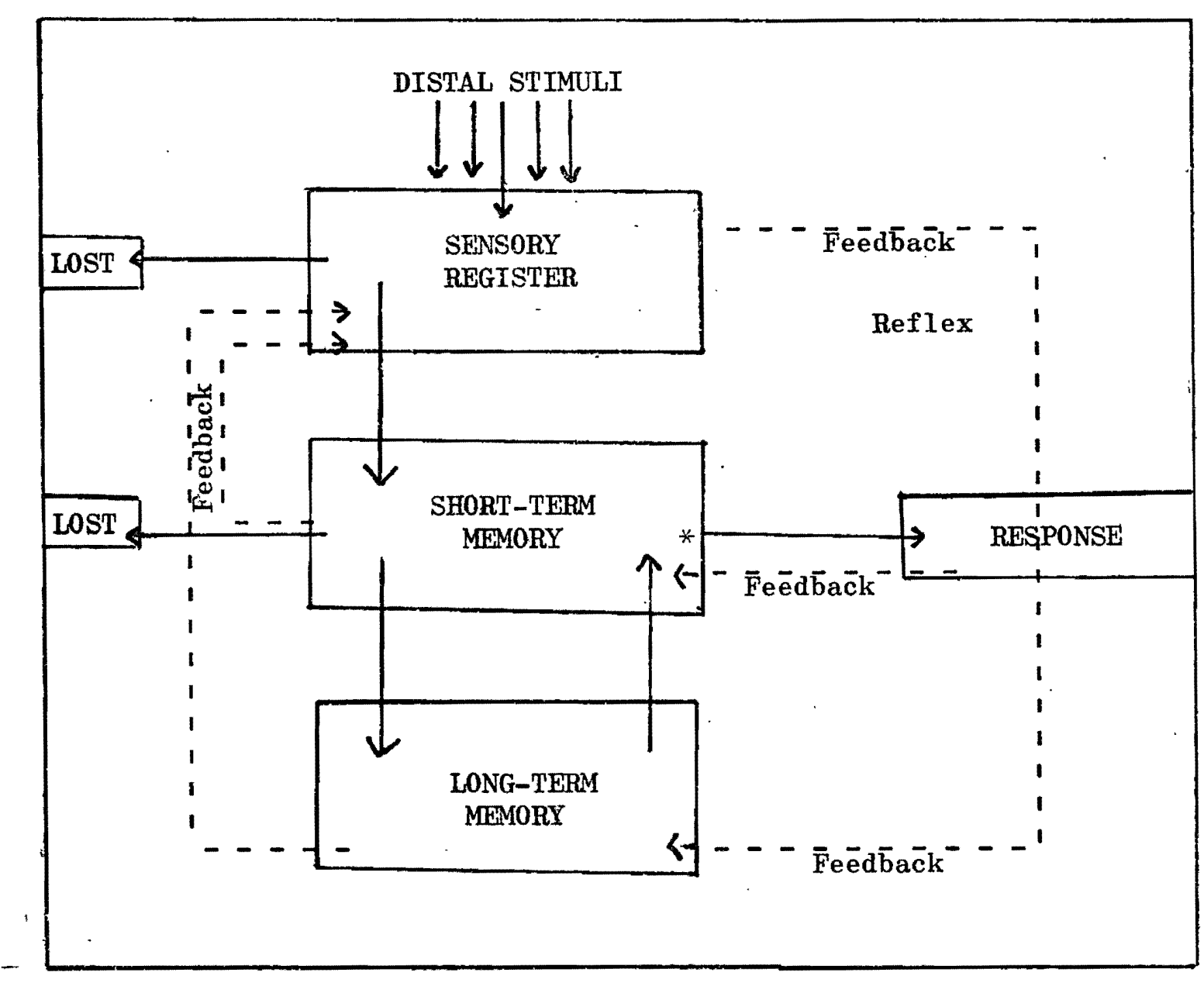

information from the distal stimuli of the outside environment reaches an individual's perceptual system is referred to as the sensory register. Since it is impossible to pick up all the information that the enviromment offers, only some of the data will be selected.

Long-Term Memory: This is where an individual files all the knowledge that he has. In the first analysis the sensory register picks up the information at birth, when perception begins. At this 
level the analysis is based on the physical characteristics of the distal stimali; we do not know it--there is no meaning assigned it--we are simply able to tell what the physical characteristics are. The information has shape, size, form, and color, and goes down into long-term memory. The information is "keyed"; long-term memory is searched for information regarding these physical characteristics. Long-term memory is permanent, even though at times a person will be unable to recall certain pieces of information. For information to be recalled, there must be an adequate amonnt of stimulus to reach it again.

Short-Term Mewory: The third element in the model is based on the assumption that the information then goes into short-term memory; any other information currently held there is added. This combination forms the percept. We have a meaningful experience; we can identify the sensation. Short-term memory represents the experience of the present; immediately thereafter it becomes a memory. Thus the experience is coded and filed in long-term memory.

A second aspect of short-term memory is that information moves from this phase into an intermediate phase (a transitional period that muns between short- and long-term memory). For example, if an individual is given a telephone number to call, it will possibly move to this intermediate phase; the number is no longer an actual experience or a thing that is now happening, but the person does have an immediate, strong memory of the experience that just happened.

A normal child, not impaired by deafness, brain damage, or other physical or psychic disorders, learns to perceive and expressively use 
prepositions by interacting wi.th the language of his environment. Eisenson (1972) lists five perceptual functional capacities that a child must have in order to acquire an oral language:

1. He must be able to receire stimuli that occur in a sequence or order.

2. He must be able to hold the sequence in mind, to hold the sequential impression, so that its components may be integrated in some pattern. This may be achieved either by memory or by the application of a rule pius memory.

3. He must be able to scan the pattern from within so that it may be compared with other stored patterns or other remembered impressions.

4. He must be able to respond differentially, to assign meaning on some level, to the identified pattern or impression.

5. In order to speak he must have an oral-articulatory system, or an equivalent manual system if he is deaf, to produce a flow or sequence of movements that constitute an utterance, audible and/or visible.

Almost all of the signals in the environment are utilized to help him is understand and express hj.s feelings and thoughts (Sanders, 1971). If all of the various environmental stimuli are utilized, why then has Menyrk (1971) observed that prepositions are often omitted from the preschool child's utterances? Brown and Bellugi (1964) explain that these omissions ocsur because the prepositions are unstressed; the child does not hear them. Bereiter and Engelmann (1966) assert:

- . in aasnal conversation, it is easy for the child to escape learning them (prepositions). Prepositions and conjunctions usually occur in situations where the context makes preaise understanding of them unnecessary. 
It could be possible that children first learn prepositions that are not as circumscribed as those that are acquired later in their development. Maybe children first learn prepositions that are used in declarative speech, such as "Put it on the table!" and at a later age learn the more complex prepositions used in rurning speech (Casteel, 1974). Another possible explanation as to why children frequently omit prepositions from their verbal expressions, is that some of these winor morphemes are more abstract than others.

Korzybski's (1958) levels of abstraction, the Structural Differential, might possibly explain why some prepositions are omitted in the expressive language of young children. The following model, as interpreted by Lee, shows how the parts of speech can be classified on a continuum from the concrete to the more abstract.

Level I, the event level, represents the inaudible "mass of atomic and subatomic detail of which our sense organs pick up only a small fraction" (Lee, 1959). This level exists independently of our nervous system.

Level II, the object level, consists of the nonrerbal images that are selected from Level $I$, the region of perception. The normally developing child abstracts the "similarities between his various sensory motor experiences and perceives his total world in selected fragments which words may be used to sjmbolize" (Lee, 1959). For example, the infant hears sootsteps, the door opens, and the mother picks up the child. Perhaps the baby will perceive these nonverbal auditory and tactuai stimuli as comforting and eventually labels them "mama." 
In Level III Lee incorporated Korzybski's levels 3, 4, and 5.

Level III $_{1}$ includes individual names, proper nouns, and words which stand for single objects or particular people. Level $\mathrm{III}_{2}$ ". . is a process of abstraction, or disregard for individúal differences" (Korzybski, 1958). Not everyone in general is called "mama"; the child abstracts the similarities and learns new words like "lady" and "man." Also, verbs, which are labels for actions, fall into this second order of verbal abstraction. Level $\operatorname{III}_{3}$ is where one word indicates and names whole groups of things by a single word. For example, a painting of geometric figures could be called a design, rather than individually labelling each part as a square, triangle and rectangle.

Level IV is the inferential level. At his level the youngster interprets and evaluates observations and descriptions. Past and future tense and question of "why" belong at this level. For example, a child can look at a picture and infer what has previously happened and what will occur in the future.

Level V represents various levels of abstraction. Lee (1959) includes prepositions; conjunctions and pronouns. Lee (1959) states:

What is the territory (the total cosmic event at a given moment) for the little words "if," "so," "even," "whether," "for," "any," "either," "about?" Without these words, one loses the grammatical constructions with which abstract thoughts are symbolized in English, the modifiers, the dependent clauses, the prepositional phrases. Without the word "if," how can you talk or think in terms of probabilities?

Some prepositions which are fairly concrete, such as "in" and "on," could be at a lower level, perhaps as low as Level III. The more abstract ones, "about" and "toward," are not used until Level V. 
Menyuk (1971) has pointed out that as the youngster's experiences expand so do his utterances, which enable him to express his experiences more completely. For an example, the early use of the prepositions "in," "on," and "off" indicates that the child is describing a state or a desired state.

The most overt use of prepositions by the child learning to talk involves those indicating place. Prepositional phrases of manner and time do not begin to appear until sometime later. Menyuk (1969) explained this by saying:

The child is in the process of acquiring a class in the language whereas at later stages, he is analyzing how the class is used in specific contexts in his language. The development of this class in the language seems to be first a general observation, perhaps simply phonological (something appears before topics) which is applied generatively and sometimes inappropriately. The child expresses a particular instance of a topic that he is dealing with at the moment. This seems to be the case in the development of prepositional phrases.

Liublenskaya (1957), a Russian linguist, disagreed with Lee and Menyuk by explaining that one of the distinctive features of minor morphemes, such as prepositions, is that the preschool child first masters them as a whole. The cogitation of a matter or object in its connections with other phenomena is a special quality of cognition. Even though the preschool child does not differentiate the prepositions, he understands the thought they express, carries out instructions when the prepositions are used in a command, and uses the connectives in his own expression. But for the child to master the relationship between objects is a matter of development and experience. 
Various structural linguistic researchers have done studies showing the developmental pattern of only a few prepositions, which might indicate that the structuralists have found that children do not acquire prepositions as a whole class. The Houston Test for Language Development (1958; Table III), C.C.D. Language Manual (1967; Table IV), Denver Developmental Screening Test (1967; Table V), Developmental Age Study (1968; Table VI), and Sequenced Inventory of Language Development (1970; Table VII) list the comprehension and expression of prepositions by chronological age. The Utah Test of Language Development (1969) tests the comprehension of "in" and "by" for children between the ages of two and three years. The Daberon (1972) tests the comprehension of "in," "under," "behind," "on," "in front of," and "next to" in threeyear-old children. The Boehm Test of Basic Concepts (1969) examines the following prepositions for kindergarten, first and second grades: "through," "next to," "inside," "around," "over," "between," "behind," "after," "below," and "above."

More generally, Lillywhite (1958) found that in the age range of three to four years the child begins to express prepositions and from four to five years he adds more prepositions to his expressive speech. When a child is ready to start school, his linguistic abilities are adequate for most situations. Bereiter and Engelmann (1966) suggest that for a child to be successful in school, he should have the ability to use the following prepositions correctly in statements describing arrangements of objects: "on," "in," "under," and "between."

A review of the literature indicates that previous attempts have not been made to determine if there is a trend for children to acquire 
TABLE III

COMPREHENSION AND EXPRESSION OF PREPOSITIONS BY CHRONOIOGICAL AGE

Prepositions tested:

"On," "under," "in front of," and "behind"

\section{Comprehension}

24 Months: Comprehends one of the prepositions.

30 Months: Comprehends two of the prepositions.

36 Months: Comprehends three of the prepositions.

\section{Expression}

36 Months: Expresses three of the prepositions. .

48 Months: Expresses all four of the prepositions.

at least twenty-six different prepositions expressively at various age levels. Nor has any research been done to determine if the socioeconomic status of a child's family will influence the acquisition of at least twenty-six different expressed prepositions.

The teacher or the speech clinician in the school or clinical setting should have an understanding of how language is acquired, plus an instrument to measure which prepositions are expressively used by a child at a given age. If the clinician determines the child is language-delayed in expressing prepositions, then the clinician should have an index whereby he way set up a program to teach the prepositions recessary so that the child may commicate with those in his environmental setting. 


\section{TABLE IV}

\section{COMPREHENSION OF PREPOSITIONS}

BY CHRONOLOGICAL AGE

\section{Months}

Responds to: "on," "under," "up," "down," "over there," and "by" when used in complete sentences.

\section{Months}

Responds to two related actions: "Run over to the chair and sit down."

\section{Months}

Follows commands: "Find the ball on the table and give it to mother." Or: "Find the spoon in the box and give it to daddy."

\section{Months}

Comprehends: "Take the book from the table and give it to mother."

\section{Months}

Responds to: "Take the dolly to mother, open the door, and bring in the baby buggy." 
TABLE V

PERCENTAGE OF PREPOSITIONS COMPREHEINDED WHEN VARIABLES OF AGE AND SOCIOECONOMIC

STATUS ARE CONSIDERED

Prepositions tested: "on," "under," "in front of," and "behind" Age when given per cent of population comprehended prepositions tested:

Comprehension of the prepositions, based on the total sample

\begin{tabular}{llll}
\hline $25 \%$ & $50 \%$ & $75 \%$ & $90 \%$ \\
\hline $2.7 \mathrm{yrs}$. & $3.1 \mathrm{yrs}$. & $3.4 \mathrm{yrs}$ & $4.5 \mathrm{yrs}$
\end{tabular}

Comprehension of the prepositions, based on occupation groups

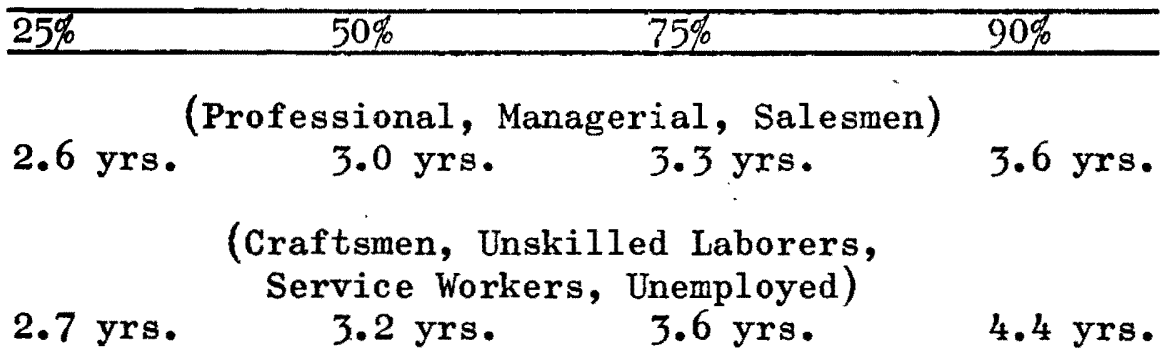




\section{TABLE VI.}

\section{COMPREHENSION AND EXPRESSION OF PREPOSITIONS BY CHRONOLOGICAL AGE}

\section{Months}

Expresses: "have clay after juice." Uses space words:

"up high," "in," "out," "fall down," and "turn around."

\section{Months}

Comprehends: "up," "down," "way up," "in here," "under the table," and "around the table."

Expresses: "Put it in."

36 Months

Understands and uses thirty-one prepositions.

Expresses: "in the train," "back over," and "around."

42 Months

Comprehends: "on," "in front of," and "behind."

\section{Months}

Comprehends: "on top of." 
TABLE VII

\section{COMPREHENSION AND EXPRESSION OF PREPOSITIONS}

BY CHRONOLOGICAL AGE

\section{Comprehension}

21-23 Months: "in."

27-29 Months: "on."

30-32 Months: "beside."

39-41 Months: "under."

\section{Expression}

30-32 Months: "in" and "on."

39-41 Months: "under" and "beside." 


\section{CHAPTER III}

METHODS AND PROCEDURES

I METHODS

$\underline{\text { Subjects }}$

The Expressive Preposition Test (EPT) was administered to a total of thirty-six children between the ages of four and nine years. There wexe six children in each of the six age groups who were tested within two months of their designated ages. Socioeconomic computations for each chilld's family, as determined by Working Paper Number Fifteen, U.S. Bureau of the Census (1963), placed one-half of the families in the upper 40 per cent and one-half of the families in the lower 40 per cent of a ten decile rarige. The thirty-six subjects, with no preference as to the sex of the child, were randomly selected from Lake Grove School, Lake 0swego, Oregon, and Providence Montessouri School, Portland, Oregon.

\section{Screening}

Childrea with reported hearing losees, physical handicaps or speech defects which would interfere with the verbal production of the prepositions were exciuded from the study. The Peabody Picture Vocabulary Test, Form A. (1965), was adninistered to all subjectso: An intelligence qnotient score of $85-115$ was required for the child to pariioipate in tha research project. 


\section{PRDCEDUHES}

\section{Evaluation}

Once the children wexe located and met the screening criteria, the EPI was administered. The subjects' verbal expression of the twenty-six prepositions was tested by having them explain where an object was located or describe a picture. (See the Appendix for a complete list of the prepositions and the manner in which they were elicited.)

The children were tested individually in a familiar, quiet room at their school. They were seated opposite the researcher, who initially put them at ease by casual conversation. If the researcher did not establish an inmediate speaking relationship with the child at the beginning of the interview, the child was not included in the study. All supplies for testing were placed on the floor by the researcher, and the stimuli for eliciting a response were presented individually. For example, when the researcher wanted to elicit the response "by," only a small toy cax was placed by a box on the table, followed by the question "Where is the car?" to elicit the response "by the box."

Occasionally, the examiner was unable to determine if the subject could correctly express the meaning of the preposition, thus indicating knowledge of the word meaning. In such instance, the examiner would make one neutral inquiry, such as: "Please explain a little more."

The EPI procedure for eliciting the responses was patterned after the Daberon (1972), "Functional Use of Prepositions" subtest. 


\section{Scoring}

All tests were administered and scored by this researcher. The tests were scored by giving one point for a correct response, regardless of the preceding verb, and no point for an incorrect response; each child could conceivably earn a total of twenty-six points.

\section{Data Analysis}

The data were analyzed by using multiple regression techniques. 


\section{CHAPTER IV}

\section{RESULTS AND DISCUSSION}

\section{RESULTS}

The purpose of this investigation was to determine if there were demonstrable trends indicating a need for normative data on the acquisition of the twenty-six prepositions tested. Answers to two questions were sought:

1. At what age levels is a given percentage of the prepositions expressively acquired?

2. Will the socioeconomic status (SES) of the child's family be a determiner as to the age at which the child will expressively use prepositions?

The sumary of statistics for the Expressive Preposition Test (EPT) is shown in Table VIII. The test was administered to the thirtysix children who ranged in age from four to nine years, with an approximated intelligence quotient range of $85-115$, and with one-half of them from families in the upper 40 per cent SES and one-half in the lower 40 per cent SES of a ten decile range. The lowest EPT score was thirteen; the highest EPT score was twenty-five, with the average score for the thirty-six children being twenty.

The analysis of variance, Table IX, indicates that if one were to look at only the age of the child, 54 per cent of the total variability would be accounted for in the child's ability to expressively use prep- 
TABLE VIII

SUMMARY OF THE STATISTICS FOR THE EXPRESSIVE PREPOSITION TEST SHOWING THE VARIABLES OF AGE, INTELLIGENCE, SES, EPT SCORE

\begin{tabular}{lrrrc}
\hline Variable & Low & High & Average & Std. Dev. \\
\hline Age & 4.0 & 9.0 & 6.5 & 1.73 \\
Intelligence & 86.0 & 115.0 & 105.2 & 7.58 \\
SES & 1.0 & 2.0 & 1.50 & .507 \\
EPT SCORE & 13.0 & 25.0 & 20.42 & 3.44
\end{tabular}

TABLE IX

ANALYSIS OF VARIANCE TABLE FOR THE EXPRESSIVE PREPOSITION TEST

\begin{tabular}{lcrcc}
\hline Source & $\begin{array}{c}\text { Degrees of } \\
\text { Freedom }\end{array}$ & $\begin{array}{c}\text { Sum of } \\
\text { Squares }\end{array}$ & Mean Square & F Ratio \\
\hline Variable: Age & 1 & 15006.00 & 15006.00 & \\
\hline Mean & 1 & 224.40 & 224.40 & 40.082 \\
Regression & 34 & 190.34 & 5.598 & $\mathrm{R}^{2}=.5410$
\end{tabular}

Variables: Age and Intelligence

$\begin{array}{lrrrl}\text { Mean } & 1 & 15006.00 & 15006.00 & \\ \text { Regression } & 2 & 241.24 & 120.62 & 22.942 \\ \text { Error } & 33 & 173.50 & 5.258 & \mathrm{R}^{2}=.5816\end{array}$

Variables: Age, Intelligence, and SES

$\begin{array}{lrrrr}\text { Mean } & 1 & 15006.00 & 15006.00 \\ \text { Regression } & 3 & 242.35 & 80.78 & 14.994 \\ \text { Error } & 32 & 172.39 & 5.387 & \mathbf{R}^{2}=.5843\end{array}$


ositions; the ratio of 40.082 with ane and thirty-four degrees of freedom is significant at the 5 per cent level. When age and intelligence were included, less than 59 per cent of the variability can be accounted for in the child's ability to expressively use prepositions. When the age, intelligence, and SES were known, SES adds less, than 1 per cent to the total accountable variability. Thus, the primary controlling variable was the chronologicai age of the child.

In analyzing the correlation coefficjents in Table $X$, one can see that the research was designed with slight correlation between age and intelligence; the range of intelligence for the children was uniform at the various age levels. There was no relationship between the ages of the children and their SES; it does not matter at what age group one looks, SES was equally distributed. Because this researcher inadvertently coded the low SES group two and the high SES group one, the results appeared to show a negative relationship between SES and intelligence; however, the intelligence scores were higher for the children from the high SES families. There also appeared to be a negative relationship between the EPI scores and SES; the EPT scores were higher for the

\section{TABLE $\mathrm{X}$}

MATRIX OF CORREIATION COEFFICIENTS SHOWING

VARIABIES OF AGE, INTELLIGENCE,

SES, EPT SCORE

\begin{tabular}{lcccc}
\hline Variables & Age & Intelligence & SES & EPT Score \\
\hline Age & 1.0 & .036 & 0.000 & .735 \\
Intelligence & .036 & 1.0 & -.360 & .228 \\
SES & 0.000 & -.360 & 1.0 & -.024 \\
EPT Seore & .735 & .228 & -.024 & 1.0
\end{tabular}


children from the high SES families. There was only a low relationship between the intelligence of the children and their EPT scores. However, there was a high positive correlation between the age of the chil-* dren and their EPT scores.

Table XI shows the average scores for each age ranging from 15.3 to 23.7 points out of a possible 26 points. The percentage of the prepositions responded to with 100 per cent success at the various age levels ranges from $30: 8$ per cent at the four-year level to 80.8 per cent at the eight-year level. As shown in this table, there were four prepositions ("beside," "toward," "until," and "about") that were never expressed by aily of the age groups 100 per cent of the time.

Additionally, Table XI indicates that 6 out of 6 children 4 years of age verbalized the following eight prepositions correctly: "around," "in," "of," "on," "out of," "to," "under," "up." At 5 years of age 6 out of 6 children expressed the following eleven prepositions correct1y: "across," "around," "at," "behind," "in," "of," "on,n "to," "under," "up," "with." At 6 years of age 6 out of 6 children verbalized the following twelve prepositions correctly: "across," "around," "from," "in," "off," "of," "on," "out of," "to," "under," "up," "with." At 7 years of age 6 out of 6 children expressed the following fifteen prepositions correctly: "across," "around," "at," "behind," "from," "in," "of," "off," "on," "out of," "through," "to," "under," "up," "with." At 8 years of age 6 out of 6 children verbalized the following twenty-one prepositions correctly: "across," "after," "against," "around," "at," "before," "behind," "between," "by," "for," "from," "in," "of," "off," 
TABLE XI

NUMBER OF CHILDEN AT EACH AGE LEVEL THAT CORRECTLY EXPRESSED THE INDIVIDUAL PREPOSITIONS

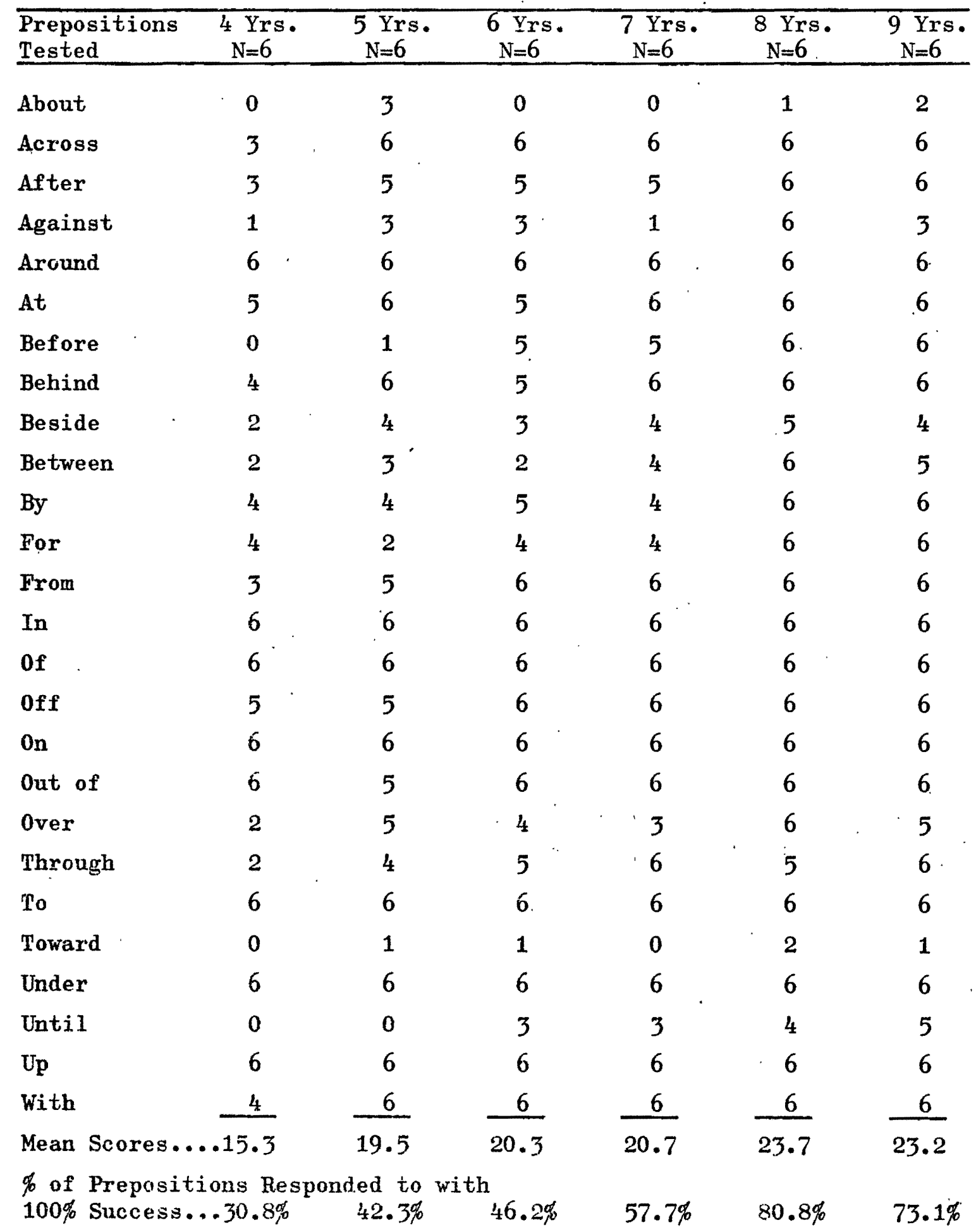


"on," "out of," "over," "to," "under," "up," "with." At 2 years of age 6 out of 6 children expressed the following nineteen prepositions correctly: "across," "after," "around," "at," "before," "behind," "by," "for," "from," "in," "of," "off," "on," "out of," "through," "to," "under," "up," "with."

\section{DISCUSSION}

The intention of this investigation was to develop an instrument to determine if there were demonstrable trends indicating a need for normative data on acquisition of the twenty-six prepositions tested. The major question asked was, "At what age levels is a given percentage of the prepositions expressively acquired?" The results, as indicated in Table $X$, show a high correlation between the age of the children and their ability to express prepositions. Table XI demonstrates that each age group, up through the eight-year-olds, verbalized a progressively higher percentage of the prepositions. Children at the nine-year-age level expressed 73.1 per cent of the prepositions, showing a decline in the percentage of prepositions correctly verbalized when compared to the eight-year-age level that expressed 80.8 per cent correctly.

A conceivable explanation for a smaller percentage of correctly expressed prepositions at the nine-year-age level would be that more children were needed for the study at each age level so that with more children included in the study it is possible that the results would appear more consistent. As shown in Figure 1, there was a wide range of EPT scores at the four- and six-year level, which further indicates the 


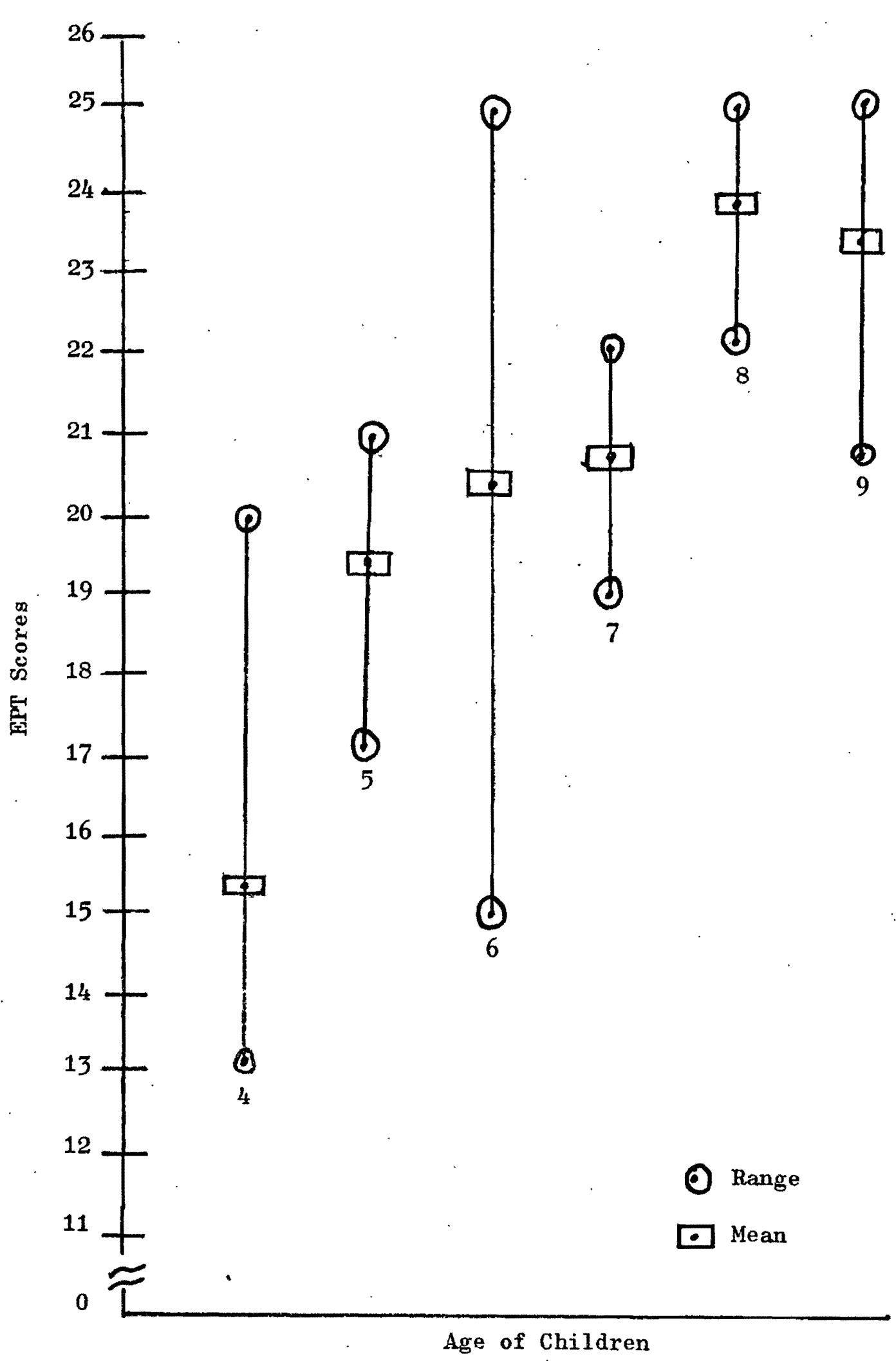

Figure 1. Ranges and means of the EPT scores for the thirtysix children ranging in age from four to nine years. 
need for a lazger number of children to be tested. Only six children were tested at each age level; therefore, individual differences in the ability to express prepositions appear to be amplified. One must recognize that this is not a longitudinal study.

The second question asked in this study was, Will the socioeconomic status of the child's family be a determiner as to the age at which the child will expressively use prepositions?" There was essentially a zexo relationship between inteliigence-SES and EPT-SES. In view of the fact that there are considerable competencies for the expression of prepositions demonstrated by the four-year-old children who were enrolled in nursery school, the effect of SES was probably less demonstrable than in two- or three-year-old children who spend the majority of their time at home. One anticipates that SES would be of more importance with children two or three years old who spent the majority of their time in the home. Assuming that their environmental circunference is smaller than that of children in nursery school, low SES negatively influences their language acquisition.

In addition to the two foregoing questions asked in this study, correlation coefficients comparing the variables of intelligence with age, SES, and EPT score, were completed, as seen in Table X. Essentially there was zero correlation between age and intelligence because of the control used in this study; intelligence quotient scores ranged from 86-115 in eacb age group. There was a slight correlation between the children's intelligence and their ability to express prepositions. This means only that within the intelligence quotient range of the 
children tested intelligence was comparatively unimportant for the expression of prepositions.

For further information on the analysis of variance for the EPT, Table IX displays a reduction of the error term, which increases the regression term by adding the three variables of age, intelligence, and SES. There was a total amount of variability in the data equal to 414.74. The question asked the computer by this researcher was: "How much of the total variability can be explained by the three variables?" The answer was that 54 per cent can be accounted for by age, intelligence accounted for 4 per cent, and SES accounted for less than one-half of 1 per cent. The probability of an Fatio as large as 40.082, when testing the hypothesis for the relationsilp between age and the probability to express the twenty-six prepositions, was less than 5 per cent; therefore, one may conclude that there was a relationship between age and the EPT scores of the children. There is a demonstrable trend which. jadicates that the more commonly used prepositions will be expressed more frequently with increasing age.

The 42 per cent unaccounted-for variability in the EPT score could be due to a number of factors. One possible explanation may be related to the child's SES, which was determined by the occupation of the fami$1 y^{\prime} s$ breadwinner; the mother's education was not considered. If the mother were a homemakex, one would expect the majority of the child's time in the home would be spent with the mother. Therefore, the mother's education and the amount of time that she spends interacting with the child could influence the child's performance on the EPT. If the mother. 
worked, then the education of the babysitter or teacher must be considered. One would also want to consider the possibility of classroom instruction on the correct use of prepositions and how it might positively influence a child's performance on the EPT. If the EPT had been more difficult or if the children with extremely high or low intelligence had been allowed to participate in the study, intelligence might have been more of an influence in this investigation.

The unaccounted-for variability might also be related to whether the child had a sibling or was an only child. Winitz (1969) referred to three language studies that ${ }_{0}$ showed significant differences in the ordinal position of the child, with a preference for the first-born child performing at a higher language level. Further, one should know if the child conmunicatively interacts with his peer group, family and teacher. If the child does not verbally interact with other people, one could assume that his performance on the EPT would be lower than that of a child of the same age $e^{\text {with }}$ verbal communication experience.

Although not conclusive, the findings from this investigation provide evidence that appear to substantiate Bereiter and Englemann's (1966) claim that prepositions are often expressed in a situation where the precise meanings are unnecessary. Many prepositions are interchangeable with other prepositions; for example, "by" and "beside" can be used to express the same meaning. Other logical substitutions expressed by the children were: "on" for "against"; "out of" in place of "from"; "up above" instead of "over"; and "in the middle of" for "between." There were four children who verbalized "intween" for "between." 
Likewise, this study confirms Menyuk's (1969) suggestion that young children first learn prepositions indicating place. The exceptions in this investigation were the four- and five-year-olds who verbalized "around," "with," and "of," which are prepositions expressing manner. More abstract prepositions showing manner and time are probably first expressed consistently after nine years of age. One may speculate that children between the ages of two and three express only prepositions showing place.

Since this investigation indicates that children acquire several pxepositions prior to the age of four, and since there appear to be demonstrable trends indicating a need for normative data on the expressive acquisition of the twenty-six prepositions tested, a suggested starting point for future testing would be at two years of age. This researcher feels that prior to collecting normative data the questions asked the children on the prepositions "toward," "until," and "about," should be rephrased so that a higher percentage of correct answers might be given by children at all age levels. Perhaps one may consider replacing the preposition "in front of" with "beside," since the latter is interchangeable with "by" and "in front of" was not included on the EPT. Clinically, once the normative data has been collected on a large number of children between the ages of two and nine, the speech clinician or teacher would have an instrument to measure whether the children are delayed in expressing prepositions. The EPT would also serve as an index indicating a starting point for teaching the prepositions necessary for effective commication at early ages. 


\section{CHAPTER V}

\section{SUMMARY AND IMPLICATIONS}

\section{SUMMARY}

Numerous linguistic studies have been done to substantiate the importance of prepositions in the English language. However, no normative studies have been made on the acquisition of expressing prepositions.

The purpose of this investigation was to determine if there were demonstrable trends which would indicate a need for normative data on the acquisition of twenty-six prepositions tested on the Expressive Preposition Test (EPT). The study set out to determine at what age levels a given percentage of the prepositions was expressively acquired and if the socioeconomic status (SES) of the child's family would be a determiner as to the age at which the child would expressively use prepositions. The EPT was administered to a total of thirty-six children between the ages of four and nine years. One-half of the children were from families af low SES and one-half were from families of high SES.

The results show a high correlation between the age of the children and their ability to express prepositions. Each age group up through the eight-year-olds expressed a progressively higher percentage of the prepositions. A statement of positive correlation between Intelligence-SES and EPT-SES was made in that those subjects in the high 
SES group scored higher on the intelligence quotient and EPT scores. Correlation coefficients indicate a slight correlation between the children's intelligence quotient which ranged from 86-115 and their ability to express prepositions.

\section{IMPLIICATIONS FOR CLINIC AND FUTURE RESEARCH}

\section{Clinic}

Nonconclusive evidence from this investigation indicates that prepositions are often expressed in a situation where the precise meanings are unnecessary because many prepositions are interchangeable with other prepositions. Therefore, when a clinician is testing or instructing the expression of prepositions and the response "by" is used instead of "beside," the clinician should consider the response correct; the same concept is required for both prepositions. The findings in this study substantiate Menyuk's (1969) suggestion that young children first learn prepositions indicating place. More abstract prepositions showing manner and tine are probably first expressed after nine years of age.

\section{Research}

There is a demonstrable trend which shows that as the child matures, there will be an increase in the expression of commonly used prepositions, indicating a necd for normative data on the expressive acquisition of the twenty-six prepositions tested. Since this investigation indicates that children acquire several prepositions before the age of four, it is suggested that future studies start testing at the two-year level. 
In addition, it is suggested that prior to collecting normative data on a large number of children that the questions asked the children on the prepositions "toward," "until," and "about," should be rephrased so that a higher percentage of correct answers might be given by the children at all age levels. It is felt that the preposition "in front of" should be tested instead of "beside," since the latter preposition is interchangeable with "by" and "in front of" was not included on the EPT. Once the EPT has been standardized for children between the - ages of two and nine, it will be a valuable instrument for measuring expressive preposition delay and an indicator for a starting point in instruction for expressing prepositions. 


\section{REFERENCES}

Baker, T., and Dudrey, M. Developmental Age Study. Portland, Oregon: Special Education, Portland Public Schools (1968).

Bayley, N. Mental Growth During the First Three Years. Genet. Psychol. Monogr., 14, No. 1, 92, as cited in McCarthy, D. Language Development in children. L. Carmichael (Ed.), Manual of Child Psychology. New York: John Wiley and Sons, Inc. (1954).

Bereiter, C., and Engelmann, S. Teaching Disadvantaged Children in the Preschool. Englewood Cliffs: Prentice-Hall, Inc. (1966).

Boehm, A. E. Boehm Test of Basic Concepts. New York: Psychological Corp. (1969).

Brown, R., and Bellugi, U. Three Processes in the Child's Acquisition of Syntax. Harvard Educational Review, XXXIV, 133-51 (1964).

Buhler, C. The First Year of Life. (Trans. P. Greenberg and R. Ripin from the following three German publications: C. Buhler and $H$. Hetzer, Inventar der Verhaltungsweisen des Ersten Lebensjahres (Quel1. Stud. Jugendk., No. 5), Jena: Fischer, 1927, 125-250 H. Hetzer and K. Wolf, Baby-tests, Zsch. Pscyol., 1928, 107, 62-204; H. Hetzer and L. Koller, Vier Testreihen fur das Zweite Lebensjahr, Zsch. Psychol., 1930, 117, 257-306.) New York: Day (1930) as cited in McCarthy, D. Language Development in Children. L. Carmichael (Ed.), Manual of Child Psychology. New York: John Wiley and Sons, Inc. (1954).

Buhler, C., and Hetzer, H. Testing Children's Development from Birth to School Age. New York: Farrar and Rinehart (1935), as cited in McCarthy, D. Language Development in Children. L. Carmichael (Ed.), Manual of Child Psychology. New York: John Wiley and Sons,

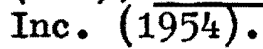

Castee1, R. Comment Made in Personal Communication, February, 1974.

Cattel1, P. The Measurement of Intelligence of Infäts and Young Children. New York: The Psychological Corporation; Lancaster, Pa.: Science Press (1940), as cited in McCarthy, D. Language Development in Children. L. Carmichael (Ed.), Manual of Child Psychology. New York: John Wiley and Sons, Inc. (1954).

Crabtree, M. Houston Test for Language Development. Houston: Houston Test Co. (1963). 
Danzer, V. A., Gerber, M. F., and Lyons, T. M. Daberon. Portland, Oregon: Daberon Research (1972).

Davis, E. A. The Development of Linguistic Skill in Twins, Singletons with Siblings, and 0nly Children from Age Five to Ten Years. Inst. Child Welfare Monogr. Ser., No. 14 (1937), as cited in McCarthy, D. Language Development in Children. L. Carmichael (Ed.), Manual of Child Psychology. New York: John Wiley and Sons, Inc. $(1 \overline{954) .}$

Day, E. J. The Development of Language in Twins: I. A Comparison of Twins and Single Children. Child Developm., 3, 179-99 (1932), as cited in McCarthy, D. Language Development in Children, L. Carmichael (Ed.), Manual of Child Psychology. New York: John Wiley and Sons, Inc. (1954).

Dewey, G. Relative Frequency of English Speech Sounds. Cambridge: Harvard University Press. (1923).

Dunn, L. Peabody Picture Vocabulary Test. Minneapolis: American Guidance Service, Inc. (1959).

Eisenson, J. Aphasia in Children. New York: Harper and Row, Publishers $\cdot(1972)$.

Fisher, M. S. Language Patterns of Preschool Children. Child Developm. Monogr., No. 15 (1934), as cited in McCarthy, D. Language DeveIopment in Children, L. Carmichael (Ed.), Manual, of Child Psychology. New York: John Wiley and Sons, Inc. (1954).

Frankenburg, W. K., and Dodds, J. B. Denver Developmental Screening Test. Boulder: University of Colorado Medical Center (1967).

French, N. R., et al. Words and Sounds of Telephone Conversations. Bell System Technical Journal, IX, 290-310 (1930).

Fries, C. American English Grammar. New York: Appleton-Century-Crofts, Inc., (1940), as cited in Streng, Alice H., Syntax, Speech and Hearing. New York: Grune and Stratton (1972).

Gesell, A. The Mental Growth of the Preschool Child: A Psychological Outline of Normal Development from Birth to the Sixth Year, Including a System of Developmental Diagnosis. New York: Macmillan (1925).

- Infancy and Human Growth. New York: Macmillan (1928).

, et al. The First Five Years of Life, A Guide to the Study of the Preschool Child. New York: Harper (1940). 
Gesell, A., Thompson, H., and Amatruda, C. Infant Behavior: Its Genesis and Growth. New York: McGraw-Hill (1934).

- The Psychology of Early Growth. New York: Macmillan (1938).

Hedrick, D., and Prather, E. Sequenced Inventory of Language Development. Seattle: University of Washington and Child Development and Mental Retardation Center (1970).

Korzybski, A. Science and Sanity. Lakeville: International NonAristotelian Library Co. (1958).

Lee, L. Brain Damage and the Power of Abstracting. ETC, XVI, 154-62 (1959).

Lillywhite, H. Doctor's Manual of Speech Disorders. J. American Medical Association, CLXVII, 851-52 (1958).

Liublinskaya, A. A. The Development of Children's Speech and Thought. In B. Simon (Ed.), Psychology in the Soviet Union. Stanford: Stanford University Press (1957).

McCarthy, D. The Language Development of the Preschool Child. Inst. Child Welfare Monogr. Ser., No. 4 (1930), as cited in McCarthy, D. Language Development in Children. L. Carmichael (Ed.), Manual of Child Psychology. New York: John Wiley and Sons, Inc. (1954).

- Language Development in Children. L. Carmichael (Ed.), Manual of Child Psychology. New York: John Wiley and Sons, Inc. (1954).

Mecham, M., Jex, J., and Jones, J. Utah Test of Language Development. Salt Lake City: Communication Research Associates, Inc. (1969).

Menyuk, P. Sentences Children Use. Cambridge: MIT Press (1969). - The Acquisition and Development of Language. Englewood Cliffs: Prentice-Hall; Inc. (1971).

Meyers, R. The Nervous System and General Semantics: III Perceptual Response and the Neurology of Abstraction. ETC, VI, 169 (1949), as cited in Lee, L. Brain Damage and the Power of Abstracting. ETC, XVI, 154-62 (1959).

Murch, G. Visual and Auditory Perception. Indianapolis: Bobbs-Merrill Co. (1973).

Pierce, J. E. A Statistical Study of Grammar and Sexicon in Turkish and Sahaptin (Klikitat). International Journal of American Linguistics, II, 96-106 (1963). 
Pierce, J. E. The Morphemes of English: Unbound Minor Morphemes. Linguistics, XLVII, 41-73 (1969).

Sanders, D. Aural Rehabilitation. Englewood Cliffs: Prentice-Hall, Inc. (1971).

Shirley, M. The First Two Years: A Study of Twenty-five Babies: Vo. II. Intellectual Development. Inst. Child Welfare Monogr. Ser., No. 7 (1933), as cited in McCarthy, D. Language Development in Children. L. Carmichael (Ed.), Manual of Child Psychology. New York: John Wiley and Sons, Inc. (1954).

Smith, M. An Investigation of the Development of the Sentence and the Extent of Vocabulary in Young Children. University Iowa Stud. Child Welfare, 3 No. 5 (1926), as cited in McCarthy, D. Language Development in Children. L. Carmichael (Ed.), Manual of Child. Psychology. New York: John Willey and Sons, Inc. (1954).

Streng, A. Syntax, Speech and Hearing. New York: Grune and Stratton (1972).

Templin, M. Certain Language Skills in Children. Minneapolis: University of Minneapolis (1957).

U.S. Bureau of the Census, Working Paper Number 15: Methodology and Scores of Socioeconomic Status. Washington, D.C. (1963).

University of Oregon Medical School, Crippled Children's Division. Language Manual (1957).

Van Alstyne, D. The Environment of Three-year-old Children: Factors Related to Intelligence and Vocabulary Tests. Teach. Coll. Contr. Educ., No. 366 (1929), as cited in McCarthy, D. Language Development in Children. L. Carmichael (Ed.), Manual of Child Psychology. New York: John Wiley and Sons, Inc. (1954).

Voegelin, C. F. Meaning Correlations and Selections in MorphologySyntax Paradigms. Bulletin of Institute of History and Philogy Academia Sinica, XXIX, 201 (1957).

Wales, R. J., and Marshall, J. C. The Organization of Linguistic Performance. In J. Lyons and R. Wales (Eds.), Psycholinguistic Papers. Chicago: Aldine, 29-80 (1968), as cited in Menyuk, P. The Acquisition and Development of Language: Englewood Cliffs: Prentice-Hall, Inc. (1971).

Webster's Seventh New Collegiate Dictionary. Springfield: G. \& C. Merriam Co. (1970). 
Webster's Third New International Dictionary. Springfield: G. \& C. Merriam Co. (1966).

Winitz, H. Articulatory Aćquisition and Behavior. New York: AppletonCentury-Crofts (1969).

Zyve, C. Conversation Among Children. Teach. Coll. Rec., 29, 46-61 (1927), as cited in McCarthy, D. Language Development in Children, L. Carmichael (Ed.), Manual of Child Psychology. New York: John Wiley and Sons, Inc. (1954). 


\section{APPENDIX}

SENTENCES USED TO ELICIT THE TWENTY-SIX PREPOSITIONS

\section{Stimulus}

1. Where is the car?

2. Where is the car?

3. Where is the airplane?

4. What did I do?

5. Where is the airplane?

6. Where is the bunny?

7. What is the car doing?

8. What is the boy doing?

9. Where is the car?

Procedure

(The examiner places a small car by a box.)

(The examiner places a small car in a box.)

(The examiner places a small airplane on a box.)

(The examiner takes the car out of the box.)

(The examiner holds the airplane over the box.)

(The examiner places the bunny under the box.)

(The examiner moves the car around the box.)

(The examiner shows the child a picture of a boy going up some stairs.)

(The examiner places a small car between two blocks.)
Response

By the box.

In the box.

On the box.

You took the car out of the box.

Over the box.

Under the box.

Going around the box.

Going up the stairs.

Between the blocks. 
10. Where is the bunny?

11. Watch! I touched the apple; then I touched the bird. I touched the bird after I touched the apple. But when did I touch the apple?

12. Where would you buy those shoes?

13. Where do we get milk?

14. What did the bunny do?

15. This is a street, and this is the sidewalk. Now watch! Dawn is walking the street.

16. The boy is leaning the tree.
(The examiner places the bunny behind the box.)

(The examiner shows the child a picture of an apple and a bird.)

(The examiner shows the child a picture of a pair of shoes.)

(The examiner shows the child a picture of a cow.)

(The examiner puts the bunny through a hoop.)

(Using a picture of a street and a small doll, the examiner walks the doll across the street. The child is initially told that when the examiner snaps her fingers and pauses, he is to say the . missing word.)

(The child is shown a picture of a boy leaning against a tree. The examiner snaps her fingers and pauses when the child is to say the missing word.)
Behind the box.

You touched the apple before you touched the bird.

At the store.

From the cow.

He jumped through the hoop.

Across.

Against. 
17. We are sitting next to each other. We are sitting each other.

18. If you wanted to take me to the store, you'd ask your Mom, "Can she go me?"

19. The car is on the box. Now where is it?

20. I'm drinking water. I got a drink water.

21. She got a new watch on her birthday. How did she get a new watch?

22. The ticket expires in June. How long is the ticket good?

23. The man left at approximately 10 o'clock. What time did the man leave? Say the whole thing.

24. The boy followed the girl. She came before the boy and he came her.
(The examiner moves beside the child, snaps her fingers and pauses when the child is to say the missing word.)

(The examiner snaps her fingers and pauses when the child is to say the missing word.)

(The examiner takes the car off the box.)

(The examiner pretends to drink water, snaps her fingers and pauses when the child is to say the missing word.)

(The examiner shows the child a doll wearing a toy watch.)

(The examiner shows the child a ticket.)

(The child is shown a picture of a man leaving the house.)

(The child is shown two pictures: one of a girl and one of a boy. The examiner places the picture of the boy behind the picture of the girl, snaps her fingers and pauses when the child is to say the missing word.)

\section{Beside.}

With.

off the box.

of.

For her birthday.

Until June.

The man left about 10 o'clock.

After. 
25. I am leaning you.

26. Where did the bunny go?
(The examiner leans toward the

child, snaps her fingers and

pauses when the child is to say

the missing word.)

(The examiner "hops" the bunny to the car.)
Toward.

(n)

To the car. 